Artículo de investigación

Cómo citar: Deaza Guáqueta

L. S. y Sánchez Arévalo L. L.

(2020). «Televisión comunitaria

en Colombia. Caso TV Suesca».

En: Mediaciones, 24 (16).

Pp. 96-109. http://dx.doi.

org/10.26620/uniminuto.

mediaciones.16.24.2020.96-109

Editorial: Corporación Universitaria Minuto de Dios, UniminUTo

Recibido: 15 de noviembre de 2019

Aceptado: 22 de mayo de 2020

Publicado: 23 de junio de 2020

ISSN: 1692-5688 | eISSN: 2590-8057

Laura L. Sánchez Arévalo

launsnchz1Agmail.com

Comunicadora social y periodista.

Editora audiovisual, productora e

investigadora social.

Lyda Shirley Deaza Guáqueta

lydasdeazalagmail.com

Comunicadora social y periodista. Investigadora, creadora y productora de contenidos para televisión local y pública.

El estudio del cual se deriva este artículo fue el trabajo de pregrado de las autoras para optar por el título en comunicación social-periodismo. Aunque la investigación la facilitó la cercanía con la entidad estudiada de una de las autoras - natural de Suesca y, además, por más de seis años, productora de TV Suesca-, las autoras declaran haber hecho esta investigación con recursos propios, razón por la cual están exentas de cualquier conflicto de interés.
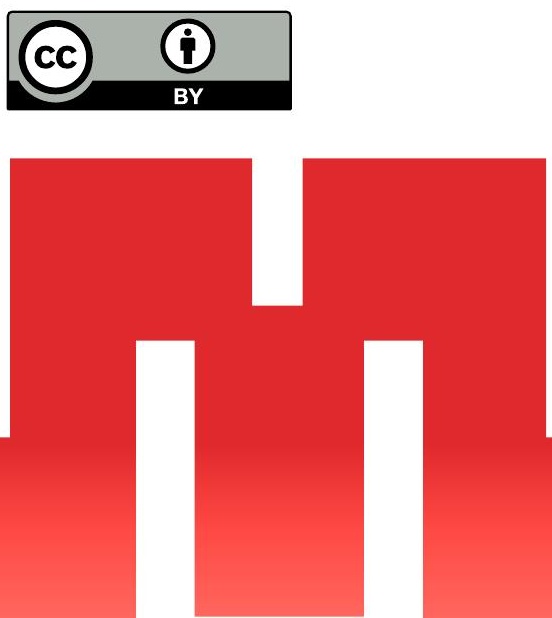

\section{Televisión comunitaria en Colombia. Caso TV Suesca}

\section{Community Television in Colombia. TV Suesca Case}

\section{Televisão comunitária em Colômbia. Caso TV Suesca}

\section{Resumen}

La revisión de la trayectoria de más de diez años de TV Suesca permite advertir, primero, la distancia entre la realidad de la televisión comunitaria en Colombia y el ideal propuesto por la ley nacional para este sector; segundo, las dificultades de su sostenimiento ante la competencia global; y, por todo ello, tercero, el paulatino menoscabo de sus principios fundacionales. Los aspectos notables de este caso podrían acusarse en forma más generalizada entre sus homólogos.

Palabras claves: medios comunitarios, televisión comunitaria, participación ciudadana, Escuela Latinoamericana de la Comunicación.

\section{Abstract}

The review of the trajectory of more than ten years of TV Suesca allows us to notice, first, the distance between the reality of community television in Colombia and the ideal proposed by national law for this sector; second, the difficulties of sustaining it in the face of global competition; and, for all these reasons, third, the gradual undermining of its founding principles. The notable aspects of this case could be accused more widely among its counterparts.

Keywords: community media, television, community television, citizen participation, Latin American School cf Communication,

\section{Resumo}

A revisão da trajetória de mais de dez anos da TV Suesca permite perceber, em primeiro lugar, a distância entre a realidade da televisão comunitária na Colômbia e o ideal proposto pela legislação nacional para este setor; segundo, as dificuldades de sustentá-lo em face da competição global; e, por todas essas razões, terceiro, o enfraquecimento gradual de seus princípios fundadores. Os aspectos notáveis deste caso poderiam ser acusados de forma mais ampla entre seus homólogos.

Palavras chaves: meios comunitarios, televisão comunitária, participação cidadã, Escola Latinoamericana da Comunicação. 


\section{Introducción}

En los años setenta y ochenta empezó a entenderse en Latinoamérica «la otra» comunicación: popular y participativa, directamente influenciada por los movimientos sociales y en postura crítica frente al modelo predominante y tradicional de la comunicación de masas. Fue una época en la que se abrió la posibilidad a escuchar nuevas voces, las de los sectores marginados e invisibles frente al Estado se convirtieron en protagonistas, para mostrar la importancia del mundo popular en la sociedad.

Los medios comunitarios, en su naturaleza y alcance, no pueden ser definidos principalmente en función de su estatus legal o de su capacidad de gestionar recursos y el alcance de sus transmisiones. Deben estar encaminados a fortalecer y facilitar el ejercicio de la comunicación en una sociedad, transformando al sujeto receptor y volverlo partícipe de la comunicación y de lo que acontece en su comunidad (Hernández Ceballos y Chaguaceda Noriega, 2013, p. 69-70).

Desde la citada precisión, los medios comunitarios se erigen como espacios locales constructores de ciudadanía, diálogo, participación y democracia, ejercicio que permite a los sujetos ser productores de información y a la vez actores del desarrollo, basados en la participación comunitaria. Así lo atestiguan los casos de comunicación comunitaria en Colombia que han logrado intervenir en el desarrollo de comunidades, a través de la participación, así como en el cambio del modelo de comunicación, en el que, superado su rol pasivo, el usuario -llámesele televidente, oyente, lector y cualquier otra denominación-se vuelve agente de cambio social. Para ello no solo se deben crear nuevas formas de participación, sino también abandonar prácticas de comunicación que inhiben la interacción con las comunidades donde se adelantan estos proyectos.

De allí la necesidad de que en estos medios de comunicación se involucre activamente la participación de las personas en las comunidades, mediante la apertura de espacios de convergencias entre diferentes voces: de campesinos, de amas de casa, de empleados, de niños, de jóvenes, etc., para cambiar la situación real y la percepción de televidentes puramente contemplativos a agentes participativos, quienes directamente pueden aportar el contenido de lo local.

En Colombia, los medios de comunicación comunitarios nacen con el objetivo de realizar y producir contenidos para satisfacer necesidades educativas, recreativas y culturales, dentro de una programación con énfasis en los aspectos social y comunitario, para garantizar el pluralismo y la democracia informativa, en una apuesta por fortalecer y facilitar el ejercicio de la comunicación en la sociedad, para transformar al receptor en partícipe y artífice de la vida colectiva local, como se ha explicado. Esto comenzó con la creación de radios locales como medios democratizadores, comprometido con darle voz a ese pueblo que, durante la historia, ha sido violentado y marginado de las dinámicas sociales, económicas, políticas y culturales del país. En el año 1947 nace Radio Sutatenza, el primer referente de medios comunitarios en el país, con la finalidad de impartir la doctrina católica y contribuir a la reducción del analfabetismo. 
Aunque previamente, de forma espontánea, en varias zonas del país se dieron procesos de comunicación comunitaria y popular, en lo concerniente específicamente a la televisión comunitaria, ella data desde la expedición de la Constitución de 1991, en la cual se establece el acceso igualitario al espectro electromagnético (artículo 75) y, así mismo, el derecho de todo ciudadano a "fundar medios masivos de comunicación" (artículo 20) libres y con responsabilidad social, a fin de garantizar «a toda persona la libertad de expresar y difundir su pensamiento y opiniones, la de informar y recibir información veraz e imparcial».

En el año 1995, mediante la Ley 182, el Congreso de la República de Colombia «reglamenta el servicio de televisión en Colombia y formula las políticas para su desarrollo, conforma la Comisión Nacional de Televisión, promueve la industria y actividades de televisión, establece normas para contratación de los servicios, reestructura entidades del sector y dicta otras disposiciones en materia de telecomunicaciones». De acuerdo con este ordenamiento, la televisión se entiende entonces como «un servicio público sujeto a la titularidad, reserva, control y regulación del Estado", cuya prestación se hará mediante concesión con entidades públicas, particulares o comunidades organizadas (artículo $1 .^{\circ}$ ). Además, se definen como fines «formar, educar, informar veraz y objetivamente y recrear de manera sana», en la búsqueda de «satisfacer las finalidades sociales del Estado, promover el respeto de las garantías, deberes y derechos fundamentales y demás libertades, fortalecer la consolidación de la democracia y la paz, y propender por la difusión de los valores humanos y expresiones culturales de carácter nacional, regional y local» (artículo $2 .^{\circ}$ ).

Allí mismo se conforma la Comisión Nacional de Televisión, CNTV, como entidad encargada de dirigir la política de televisión, desarrollar y ejecutar los planes y programas del Estado en relación con el servicio público de televisión; regular el servicio de televisión, e intervenir, gestionar y controlar el uso del espectro electromagnético utilizado para la prestación de dicho servicio.

A partir de esta norma se clasifica el servicio de televisión (artículo 18) en función de la tecnología principal de transmisión utilizada (televisión radiodifundida, cableada y cerrada, satelital), de los usuarios del servicio (abierta o por suscripción), de la orientación general de la programación (comercial, de interés público, social, educativo y cultural) y los niveles de cubrimiento del servicio (nacional de operación pública o privada, regional, local y comunitaria).

En el año 1999, a través del Acuerdo 6, la entonces CNTV reglamenta la prestación del servicio de televisión comunitaria sin ánimo de lucro, o simplemente televisión comunitaria, y establece la obligación de realizar y producir su propia programación para satisfacer necesidades educativas, recreativas y culturales a través del canal de producción propia 0 canal comunitario, el cual debe reflejar la cultura, los temas y las necesidades de la comunidad a la que se dirige.

En el año 2006 se expide el Acuerdo 9 y se establece que los usuarios del servicio de televisión prestado por comunidades organizadas sin ánimo de lucro tendrán derecho a 
producir contenidos de manera independiente para ser emitidos a través del canal o los canales de producción propia (artículo 18).

En abril de 2012 desaparece la Comisión Nacional de Televisión y aparece la Autoridad Nacional de Televisión, ANTV (Ley 1507), como entidad gubernamental regulatoria de la televisión con el fin de velar por el acceso a la televisión, garantizar el pluralismo e imparcialidad informativa, la competencia y la eficiencia en la prestación del servicio, así como evitar las prácticas monopolísticas en su operación y explotación, en los términos de la Constitución y la ley. Las demás competencias se redistribuyen entre la Agencia Nacional del Espectro, ANE; y la Comisión de Regulación de Comunicaciones, CRC.

Durante el ejercicio administrativo, la ANTV determinó características específicas para el funcionamiento de los canales de televisión comunitaria creados dentro de los sistemas de televisión por cable (Resolución 650 de 2018), que, entre otras medidas, establece que todo operador del servicio de televisión comunitaria debe emitir a través del canal comunitario un tiempo mínimo de programación basado en la producción propia de acuerdo al número de asociados (artículo 21) así: con un número inferior o igual a 500 asociados, tres (3) horas semanales; superior a 501 y hasta 1.000, cuatro (4) horas semanales; superior a 1.001 y hasta 3.000 asociados, cinco (5) horas semanales; con un número superior a 3.001 y hasta 6.000 asociados, seis (6) horas semanales. Frente a la comercialización a través del canal comunitario (artículo 22), establece que podrá comercializar hasta seis (6) minutos por cada media hora de programación y hacer transmisión de mensajes de interés para la comunidad (artículo 23) de forma gratuita.

En julio de 2019 el Congreso de la República de Colombia expide la Ley 1978 de 2019 por la cual se moderniza el sector de las tecnologías de la información y las comunicaciones, TIC, se distribuyen competencias, se crea un regulador único, se liquida la ANTV y se redistribuyen las funciones de esta desaparecida entidad entre el Ministerio de Tecnologías de la Información y las Comunicaciones, la Comisión Nacional de Comunicaciones y la Superintendencia de Industria y Comercio.

En el artículo 32, en lo referente a las organizaciones de televisión comunitaria sin ánimo de lucro, se establece que conservarán su naturaleza jurídica de acuerdo con las normas que les sean aplicables con la entrada de la nueva legislación. Y se especifica que deben continuar con el cumplimiento de todas las demás obligaciones de origen legal, reglamentario y regulatorio, aplicables al servicio de televisión que prestan.

A partir de esto, la televisión comunitaria es entendida como un servicio público de carácter informativo con enfoque social que cumple la función de puente entre la televisión y los ciudadanos, permitiendo ver sus expresiones culturales, artísticas y religiosas, convirtiéndose así en un espacio de expresión local. Los casos de comunicación comunitaria en Colombia han logrado intervenir en el desarrollo de comunidades a través de la participación (Márquez Gómez, L., 2013), lo cual demuestra la necesidad de crear nuevas prácticas de comunicación que permitan la interacción con las comunidades, en un ejercicio de reciprocidad en el que el sujeto se convierte en productor de información y agente de cambio social. 


\section{Antecedentes}

En Colombia encontramos un número significativo de experiencias de televisión comunitaria (setecientas cinco, según el Directorio de Operadores de TV Comunitaria) junto con otras iniciativas de comunidades que han buscado representarse a través de los audiovisuales, que, aun con sus importantes impactos sociales, han sido muy pocas veces registradas, razón que dificulta su documentación y el conocimiento más amplio de las dinámicas de participación de las comunidades en sus medios.

La primera investigación a este respecto, en 1998, con el apoyo de la Fundación Social, el Centro de Investigación y Educación Popular Cinep, y el Ministerio de Comunicaciones, fue un diagnóstico titulado Señales de humo: panorama de la televisión local y comunitaria en Colombia, suscrito por Enrique Rodríguez, Luis Fernando Barón y Julián Tenorio, coordinadores del grupo de trabajo con cual, en el año inmediatamente anterior, 1997, recogieron y testimoniaron la cantidad y diversidad de experiencias de la televisión comunitaria de entonces, sus procesos históricos (Téllez Garzón, M. P., 2005, 142-145) y, a partir de ellos, reconocieron su importancia en la vida cotidiana de las comunidades.

El mismo trabajo y otros de la citada profesora María Patricia Téllez Garzón tratan sobre la realidad de la televisión comunitaria en Colombia, su origen, la manera cómo evolucionó, las condiciones tecnológicas y legislativas que hicieron posible su aparición hasta llegar a una caracterización de la televisión comunitaria basada en los distintos diagnósticos que sobre ella se han realizado, los hallazgos y limitaciones detectados y el balance de la situación actual de este medio.

Ya en lo conceptual, hablar de televisión comunitaria nos impone adoptar la perspectiva de la Escuela Latinoamericana de la Comunicación, centrada en nuestra realidad social, económica y política, cimentada en la idea de emancipación en torno a la cultura y a la comunicación. En los años sesenta, ésta se erige como una postura crítica, ya que proponía una comunicación para el desarrollo entendida como un proceso bidireccional, dialógico y participativo, que implica la comprensión de las personas, sus creencias y valores y sus normas sociales y culturales. Todo ello con la recuperación de memoria histórica, la construcción de tejido social, el fortalecimiento de la esfera pública y de los intereses colectivos, la generación de prácticas de reconocimiento e inclusión, la visibilización de conflictos y discursos de los excluidos y la consolidación de las ciudadanías y la democracia, con herramientas y enfoques de comunicación que potencien a los individuos y a las comunidades con el propósito de transformación social y mejoras en la calidad de vida.

Dentro de esta escuela encontramos a teóricos como Jesús Martín Barbero, Néstor García Canclini, Rosa María Alfaro, Alfonso Gumucio, entre otros. Jesús Martín Barbero y su análisis de la cultura, se refiere al estudio de la globalización desde la semiología, a la relación de los medios con sus públicos y, en especial, a la forma como estos interpretan cada contenido. En su libro De los medios a las mediaciones (2011) posa la mirada del otro lado del proceso de la comunicación, la recepción, hecho de las resistencias y las variadas formas de apropiación de los contenidos de los diferentes medios, donde la comunicación se cruza con las diferentes redes que la configuran como un fenómeno 
complejo. De igual forma recalca las diferencias entre lo masivo y lo popular, de lo cual deriva su crítica ante la función de los medios en el aspecto cultural y social.

En los últimos años hemos sido testigos de los grandes cambios en Latinoamérica en los ámbitos político, tecnológico, social y cultural, igualmente en los medios de comunicación, donde encontramos no solo radio y prensa, sino que se le suman televisión e internet, cada uno con fines diferentes en cuanto a la transmisión de contenidos y el público al cual va dirigido. Sin embargo, no todos estos medios de comunicación cumplen con la tarea de comunicar. El hecho de comunicar implica una interacción constante entre el medio y el receptor, como lo afirma Frances Berrigan (1981, p. 6): «Si bien los medios de comunicación son de gran valor para el desarrollo, nunca son eficaces si se utilizan aisladamente y si no van acompañados de cambios prácticos en la estructura orgánica, política y social de cada país», y esta ha sido la manera en que se han desarrollado los medios de comunicación durante décadas en el territorio latinoamericano.

Sobre Colombia, encontramos un modelo de televisión expuesto por Alfonso Gumucio (2008) como respuesta al vacío de comunicación creado por los medios tradicionales que no tienen en cuenta las voces locales, con el objetivo de rescatar el pálpito de la comunidad y el pulso de la vida cotidiana, mediante el fortalecimiento de una relación dialógica entre productores y comunidad. Para integrar este modelo al marco comunitario, el autor menciona las siguientes condiciones indispensables:

1. Participación comunitaria: Este medio no nace de un interés comercial o político, debe ser un «proceso genuino de participación» en el que «la comunidad se apropia del instrumento de comunicación" interviniendo en todo el proceso de producción, control y gestión, garantizando la sostenibilidad y permanencia en el tiempo.

2. Contenidos locales: lo que realmente diferencia a una televisión comunitaria de una televisión comercial es la emisión de contenidos locales, y el desarrollo de un lenguaje propio, es decir, una forma particular de ver y contar los hechos. Sus contenidos se refieren a temas de salud, educación, la recuperación de la memoria histórica de los pueblos, democracia y ciudadanía, convivencia pacífica, medio ambiente, civismo y organización social, sin dejar de un lado los aspectos lúdicos representados en las fiestas, música local, etc.

3. Tecnología apropiada: «Lo apropiado en una televisión comunitaria es una tecnología cuya relación costo-beneficio sea razonable, cuyo manejo esté al alcance de técnicos, y cuya gestión pueda ser asumida por miembros de la comunidad».

4. Pertinencia cultural y lengua: esta televisión tiene el compromiso de elaborar «una propuesta estético-televisiva y cultural» propia, correspondiente con los modos de vida de su audiencia: sus valores, su identidad, incluso sus ritmos vitales, los que deben tenerse en cuenta para el establecimiento de sus franjas horarias.

5. Convergencia: con la eliminación de las fronteras físicas gracias a los avances tecnológicos, como el internet, la televisión comunitaria puede mostrar al mundo sus logros y adelantos a través de esta red, así como establecer alianzas, evitar el aislamiento. 
La televisión comunitaria tiene la misión de innovar, crear otros géneros diferentes de la televisión comercial, y ser aceptada popularmente como una televisión de calidad. Debe ser ampliamente democrática e incentivar la postura crítica, participativa y propositiva. Los denominados medios comunitarios sin duda son impulsores de la comunicación participativa, puesto que se caracterizan por la centralidad que ocupa la participación de la ciudadanía no sólo en la construcción de los mensajes que se difunden, sino también en su gestión y en los procesos de cambio social que se impulsan.

Entendemos la comunicación participativa como aquella que «busca la emancipación de las personas, alentando el diálogo horizontal para el reconocimiento de los problemas comunitarios y la búsqueda de soluciones» (Gumucio, A. y Tufte, T., 2008, p. 1.041). Desde esta perspectiva, el enfoque participativo de la comunicación y el proceso del cambio social que ella genera son más importantes que los productos, porque precisamente durante el proceso de comunicación no solo se reconoce el contexto en el que se interactúa, sino se inicia la transformación.

La participación de las personas en los medios comunitarios es clave importante para convertirlos realmente en medios ciudadanos, esta participación se da para disminuir inequidades y desigualdades sociales, promover derechos, democratizar la gestión pública, y es un mecanismo de expresión entre el medio y la sociedad. La antropóloga Jeanine El'Gazi en el artículo "La experiencia de las emisoras ciudadanas y comunitarias, o cómo hablar de cara al futuro más allá de un conflicto armado" señala que la participación debe gestionar y organizar los medios comunitarios traspasando lo comunicativo para impregnar las prácticas sociales transformadoras. De esta forma la participación ciudadana efectiva en los medios comunitarios promueve la cultura local y contribuye al desarrollo social (El'Gazi, J., 2011). Los procesos participativos y las relaciones que se dan entre el medio comunitario y las personas son «la razón de ser de una experiencia de comunicación comunitaria» (Gumucio, A., 2008).

Guy Bessette (2004) señala que la comunicación participativa, para el desarrollo, alternativa, para el cambio social, o para la paz. Surge en la década de los ochentas en el contexto de la Escuela Latinoamericana, para reconocer a la comunicación como un proceso bidireccional que trasciende la difusión de mensajes e información. Bajo este enfoque ya no se trata sólo de difundir un mensaje, sino que apunta a establecer puentes, vínculos y redes de comunicación. Así mismo Carlos del Valle Rojas considera que esta comunicación «analiza y evalúa críticamente el proceso de comunicación, desdela estructura, organización, producción, circulación, consumo y comprensión» (Del Valle Rojas, C., 2019, p. 149).

Por su parte, Jan Servaes y Patchanee Malikh (2007, p. 48) plantean que debe aumentar significativamente «el involucramiento del público en el proceso de producción y también en la gestión y la planificación de los sistemas de comunicación», donde complementan apoyados en Frances Berrigan (1981, p. 20) - el acceso posibilita a las comunidades «escoger programas variados y relevantes, teniendo medios de retroalimentación para transmitir sus reacciones y demandas». Además, permitir que el público ejerza el poder de la toma de decisiones al interior de los medios de comunicación. 


\section{Canal comunitario TV Suesca}

Entre de los medios comunitarios colombianos encontramos el caso de TV Suesca, ubicado en el municipio homónimo del departamento de Cundinamarca. TV Suesca Canal 8 fue fundado el 13 de marzo de 2004 por la Asociación de Copropietarios Antena Parabólica de Suesca, encabezada entonces por Pedro Héctor Sintura Arévalo, quien funge como director general del medio, creado, pues, por los propios habitantes de la comunidad, sin ánimo de lucro y para prestar al municipio el servicio de televisión por cable. Su primera emisión fue un informativo de treinta minutos llamado Notisuesca, presentado por estudiantes del Colegio Gonzalo Jiménez de Quesada. El canal surgió por la necesidad de crear un modelo de TV comunitaria orientado hacia el desarrollo de la comunidad, que democratizara la labor informativa y fomentara la participación de los habitantes en la elaboración de los contenidos, en el control y en la gestión del medio para la consecución de metas colectivas.

Desde su constitución apostó a ser un medio que representara lo que son los suescanos, mostrar los acontecimientos que surgen dentro de la comunidad y las problemáticas que atraviesan diferentes sectores del municipio. Pretendió no sólo experimentar con la comunicación comunitaria, sino dar voz a la población suescana, mostrar a la vez su idiosincrasia, rescatar su identidad, cultura y tradiciones, para constituirse como un medio de comunicación participativo, democrático y cultural.

En este proyecto han participado más de mil habitantes entre niños, jóvenes y adultos, que sin ningún conocimiento sobre producción televisiva han logrado llevar a los hogares programación con contenido informativo, educativo, cultural y de entretenimiento.

En la actualidad, el canal emite por el canal 8 del sistema de televisión por cable, tiene alcance dentro de todo el casco urbano y, de las diecinueve veredas, se extiende a solo tres: Palmira, Cuaya y Cacicazgo. La programación central está compuesta por el informativo Notisuesca; Especiales TV Suesca, sobre eventos locales; la transmisión de la eucaristía de los domingos; Senderos, un programa de discusión política; Caja de sorpresas, en la franja infantil; Proyecto $S$, dirigido a jóvenes; y Vida de padres, un programa de educación. El canal cuenta con sede propia, compuesta por sala de producción, estudio de grabación y sala de edición de contenidos.

\section{Contexto}

En sus inicios, TV Suesca pretendió hacer una labor social de trabajo comunitario, llevando las cámaras del medio a todos los rincones de la comunidad, tanto en el casco urbano como en el sector rural, a las instituciones educativas y a las diferentes organizaciones, para motivar a narrar y a denunciar a través del medio las problemáticas del territorio, visibilizar sus propuestas de solución y dar vía libre a la comunidad para decidir los temas de interés, convirtiéndose así en un instrumento de participación ciu- 
dadana. Sin embargo, al hacer una lectura rápida del rol que actualmente cumple este medio, se percibe que TV Suesca, con el paso de los años, ha adoptado prácticas más frecuentes en los medios tradicionales que tienden a alejarlo del interés y de la participación de la comunidad, originalmente buscados. Tras dieciséis años de funcionamiento, los cambios en la dirección del canal han afectado la continuidad en la emisión de programas y han conllevado también un aumento de la rotación de los participantes de la experiencia, entre otras problemáticas que han ido mutando las dinámicas de un medio inicialmente comunitario.

Una retrospección a esta experiencia de comunicación permite reconstruir y reflexionar sobre los aportes que este medio de comunicación ha hecho a la construcción de ciudadanía y democracia y a través de qué mecanismos de participación de los habitantes del municipio, reconocer las características de la comunicación alternativa que TV Suesca ha ido perdiendo y los factores que han incidido en ello y, finalmente, comprender su sistema de producción actual.

\section{Proceso de investigación}

Esta investigación permite enfocar en un caso el desarrollo de la televisión comunitaria en Colombia, por lo cual es probable que no aluda a una situación aislada, sino que revele realidades más generalizadas sobre el funcionamiento de estos procesos comunitarios. Además, comprender la realidad del ejercicio de televisión comunitaria contrapuesta a la legislación que la regula y conocer la percepción de los involucrados de TV Suesca frente a los diversos factores que intervienen en el ejercicio de televisión comunitaria.

Está investigación es de carácter cualitativo y pretende comprender, con el uso de la sistematización de experiencias y entrevistas a profundidad, el rol que ha ejercido TV Suesca en la construcción del concepto y ejercicio de la participación ciudadana. Además, se realiza análisis crítico de medios que permite comprender la lógica de producción de los contenidos emitidos durante los años de funcionamiento y las características que constituyen hoy a TV Suesca como medio alternativo y de participación. Con ello se ilustran algunos factores a los que se ven sometidos estos canales comunitarios y se subraya su importancia al posibilitar la comunicación bidireccional, que incluso puede ser más relevante e influyente en la vida cotidiana de los sujetos, y que muchas veces desaparece sin ser percibida, incluso entre las comunidades en las que intervienen.

Consecuentemente, esto es al mismo tiempo un ejercicio de memoria colectiva materializada en la realización de un documental en el que se resuelven algunos interrogantes generales del trabajo realizado por TV Suesca. En el documental, las personas cuenten su realidad y la percepción propia de las dinámicas de participación.

En su trayectoria TV Suesca no ha sido un tema de investigación, de análisis y mucho menos ha participado en la reconstrucción de su memoria como medio. Por ello, recoger y valorar la experiencia genera apropiación y posibilita el aumento de la parti- 
cipación ciudadana al reconocer este medio de comunicación como propio. Documentamos luchas, aciertos, desaciertos y las situaciones que lo consolidan como uno de los principales procesos de participación en Cundinamarca.

Fue entonces, también, un ejercicio periodístico en el que se abordaron diferentes posturas de sus protagonistas: las comunidades, los medios, quienes han intentado legislarla, pero también aquellos académicos que dedicaron parte de su formación a entender y aportar a la idea de televisión comunitaria en nuestro país.

Todo lo anterior conduce a la proposición de estrategias de comunicación en pro de reconocer y rescatar la identidad ciudadana y cultural.

Animaron la investigación la búsqueda de respuestas a preguntas tales como: ¿Cómo fue concebida esta televisión en nuestro país? ¿Cómo se entiende la participación ciudadana desde los ideales teóricos? ¿Qué hace un medio como TV Suesca para generar participación? pero también ¿Cómo una comunidad siente o no su participación?

El proceso de investigación lo dividimos en dos momentos: en el primero se hizo consulta bibliográfica y acercamiento a la comunidad; y en el segundo, la producción y postproducción del documental. Estos momentos tuvieron 3 fases complementarias:

1. Consulta bibliográfica de los trabajos sobre televisión comunitaria en Colombia, para identificar aspectos de interés sobre el tema, teóricos y expertos dedicados a analizar estos procesos.

2. Revisión de material de archivo, fuentes bibliográficas y testimoniales sobre el proceso de este canal comunitario durante trece años, con el fin de identificar fuentes que reconstruyeran diferentes aspectos de la experiencia de televisión comunitaria.

3. Conversaciones con expertos sobre el tema, tanto académicos como ex funcionarios de la entidad rectora de la televisión, miembros de la junta directiva del canal, participantes, ex participantes de la experiencia y televidentes, con el propósito de conocer el tema desde varias perspectivas.

La recolección de la información se realizó a través de entrevistas desarrolladas con una guía de preguntas de acuerdo a la fuente (académicos, expertos, ex funcionarios, directivos canal, participantes de la experiencia, ex participantes y televidentes). Esta guía fue un derrotero flexible para los investigadores y no una camisa de fuerza para la fuente, lo que se tradujo en conversaciones, con el fin de reconstruir el proceso de Televisión Comunitaria.

Los grupos de entrevistas se dividieron así:

1. Expertos y académicos: quienes construyen conceptos básicos para entender la televisión comunitaria, que se ha formado no solo desde las normas, sino desde las in- 
vestigaciones académicas. Permiten conocer cómo se desarrollan hace algunos años estos procesos en Colombia.

2. Representantes del medio: miembros y ex integrantes, quienes reconstruyen el proceso de formación de la experiencia y analizan desde los diferentes aspectos cómo ha reaccionado el canal.

3. Televidentes: son el aporte crítico, pues a través de ellos, como principales receptores del canal, se puede entender cómo se han dado estas dinámicas.

En el trabajo de campo se hizo la grabación de testimonios que construyen el contenido desarrollado en la pieza audiovisual. Todas las entrevistas fueron filmadas con equipos profesionales, cámaras Canon 70D y Nikon 500D, micrófono de solapa y trípode de soporte. Para el trabajo de producción se organizó una base de datos de los contactos realizados e igualmente se diseñó un release, firmado por cada una de las fuentes entrevistadas.

Nos motivamos a desarrollar un proyecto cuyo producto final fuera un documental audiovisual porque este formato explora personas y situaciones reales, sirve como testigo y además como un archivo al cuál se podrá recurrir para futuras investigaciones.

El documental, como otros discursos de lo real, conserva una responsabilidad residual de describir e interpretar el mundo de la experiencia colectiva, una responsabilidad que en modo alguno es una cuestión menor». Es más, conjunta estos otros discursos (de ley, familia, educación, economía, política, Estado y nación) en la construcción auténtica de una realidad social (Nichols, B., p. 40).

\section{Aprendizajes y reflexiones}

$\mathrm{Al}$ hacer nuestro trabajo de campo y entrevistar a los participantes del canal TV Suesca, percibimos que las características que exige la ley para el funcionamiento de los medios comunitarios en la realidad del funcionamiento del canal, esas características no se dan. es muy difícil que se pueda cumplir con la reglamentación. A futuro esta situación puede llevar al canal a desaparecer, al igual que otras experiencias.

El canal realizó una labor social de trabajo comunitario al llevar sus cámaras a todos los rincones de la comunidad, tanto en el casco urbano como en el sector rural, a las instituciones educativas y a las diferentes organizaciones, al motivar a narrar y denunciar las problemáticas del territorio, al visibilizar sus propuestas de solución y dar vía libre a la comunidad para que decidiera los temas sobre los que quería hablar. Actualmente, las personas que ven el contenido del canal lo hacen para informarse de todas las actividades particulares de Suesca y pocos son los que participan activamente para fortalecer el canal. Esta experiencia ha sido un proceso no solo de supervivencia a los cambios tecnológicos, administrativos, culturales sino también a cambios frente a las dinámicas de participación comunitaria y de consumo de televisión de los ciudadanos. 
En las exigencias de ley, nos damos cuenta de que en la mayoría de los procesos estas dinámicas de participación comunitaria se manifiestan de diferentes formas. En general, los contenidos de los canales deben ser enfocados en representar los intereses de la población a la que tienen alcance y deben ser generados por la comunidad, con base fundamental en la participación ciudadana. Y es aquí donde la brecha entre la ley y realidad se amplía cada vez más. Si bien el ideal de los medios comunitarios es su fortalecimiento por personas interesadas que deseen participar en la elección, elaboración del contenido y gestión del medio, nos damos cuenta de que esta participación no llega a ser efectiva. En las entrevistas que recolectamos, al hablar con la comunidad, entendimos cómo sus miembros perciben la participación y no es generando contenidos o teniendo voz en las decisiones del canal. La comunidad se siente partícipe en la medida en que se siente representada sin intervenir activamente en el desarrollo del canal.

La comunidad escenario de TV Suesca identifica al canal como el medio donde pueden conocer de primera mano lo que sucede en el municipio. La principal crítica que manifiesta la audiencia al canal es la repetición de la programación y, al tener al alcance una amplia oferta de canales comerciales, prefiere esos contenidos que resultan más entretenidos y variados frente al contenido del canal comunitario. Los errores técnicos, de igual forma, contribuyen a que sea menos atractiva la programación.

Al involucrarnos con el proceso de televisión comunitaria, conocimos una realidad desfavorable que enfrenta el medio: el sostenimiento. Estos canales de contenido educativo, cultural, no comercial, se ven obligados a sobrevivir con los recursos que limitadamente les otorga el sistema de parabólica, porque ni siquiera su apuesta por la pauta comercial es efectiva. Junto a esta realidad se le suma la llegada de diferentes operadores de televisión, que día a día cautivan más usuarios.

En el caso específico de TV Suesca, los niños y jóvenes son los que más han participado del proceso, lo que ha impactado su proyecto de vida, el de estos sectores de la población. Varios de los jóvenes involucrados en esta experiencia encontraron su rumbo en la comunicación social, la realización en medios audiovisuales y áreas afines.

Latelevisión comunitaria en TVSuescahasidoun ejercicioverdaderodeparticipación que permite el fortalecimiento y protección de la identidad cultural, la ciudadanía reconoce al canal como el archivo histórico del municipio y esto se ha construido codo a codo con los ciudadanos. Esto es posible por medio de una comunicación enfocada en el desarrollo de las comunidades, una comunicación participativa, desinteresada, democrática y a disposición de todos.

Acercarnos a la experiencia del canal comunitario Tv Suesca Canal 8 nos permitió entender que el proceso de televisión comunitaria no solo impacta la vida de los involucrados directamente en el proceso, sino que influye a todos aquellos que reciben la señal al tener una producción y programación enfocada en la cotidianidad del territorio.

El futuro para el proceso del canal comunitario no es esperanzador, porque está limitado por la legislación que lo regula, más enfocada en beneficiar a los grandes 
operadores de la televisión por cable que en la protección de los canales comunitarios, lo que, de paso, restringe su crecimiento y su profesionalización.

Durante este proceso de investigación tuvimos la oportunidad de conocer un espacio de participación pocas veces reconocido en la academia, pero espacio de fortalecimiento del ejercicio de la comunicación social y el periodismo. Por ser este un tema poco estudiado en las aulas de las escuelas de comunicación, queremos incentivar la conversación alrededor de la importancia del medio comunitario como un escenario auténtico de participación y protección cultural. Además, mostrar a estos medios como espacios para desarrollar investigaciones y también como apoyo para la realización de proyectos de desarrollo social.

El servicio de televisión comunitaria es importantísimo para el desarrollo del país, porque ayuda a la difusión de información, al pluralismo y a la consolidación de la democracia. Estos canales comunitarios que, sin lugar a dudas, han mantenido la identidad de un país inmensamente variable, deben ser fortalecidos por comunicadores, trabajadores sociales, entre otras carreras, porque ésta es la televisión posible.

\section{Referencias}

Berrigan, F. (1981). La comunicación comunitaria. Cometido de los medios de comunicación comunitaria en el desarrollo. París: Unesco. http://unesdoc.unesco.org/images/0013/001343/134355so.pdf

Bessette. G. (2006). «Facilitar el diálogo, el aprendizaje y la participación para el manejo de los recursos naturales». En: Comunicación y desarrollo sostenible. Roma: Organización de las Naciones Unidas para la Agricultura y la Alimentación. Pp. 91-118. https://studylib.es/doc/4460530/facilitar-el-di\%C3\%A1logo--el-aprendizaje-y-la-partiсірасі\%C3\%B3n-p...

Comisión Nacional de Televisión (2006). Acuerdo 009. (2006). http://www.antv.gov.co/sites/default/files/acuerdo_009.pdf Alcaldía de Suesca - Cundinamarca (2016). Disponible en: http:// www.suescacundinamarca.gov.co/indicadores.shtml\#poblacion [Acceso 17 may 2016]

Del Valle Rojas, C. (2019). «Comunicación, Participación y Desarrollo. Algunas aproximaciones genealógicas desde el contexto latinoamericano». En: Revista Internacional de Comunicación y Desarrollo, n. ${ }^{\circ} 10$, vol. 3. Santiago de Compostela: Universidad de Santiago de Compostela. Pp. 147-158. https://dialnet.unirioja.es/servlet/articulo?codigo=7155139 
El’Gazi, J. (2011). «La experiencia de las emisoras ciudadanas y comunitarias, o cómo hablar de cara al futuro más allá de un conflicto armado». En: Comunicación, desarrollo y cambio social. Interrelaciones entre comunicación, movimientos ciudadanos y medios. Pereira, J. M. y Cadavid, A. (eds.). Bogotá: Editorial Pontificia Universidad Javeriana. Pp. 299-311. https://javeriana.edu.co/unesco/pdf/comunicacion_desarrollo_cambio_ social2.pdf\#page $=296$

Gumucio, A. y Tufte, T. (2008). Antología de la comunicación para el cambio social. La Paz: Editorial Plural.

Gumucio, A. (2008). «La televisión comunitaria. Ni pulpo, ni púlpito: pálpito». En: Etcétera, revista de medios mensual. México. Pp. 56-67. https://www.academia.edu/1365125/ La_televisi\%C3\%B3n_comunitaria_Ni_pulpo_ni_p\%C3\%BAlpito_p\%C3\%A1lpito

Hernández Ceballos, I. y Chaguaceda Noriega, A. (2013). «La comunicación alternativa y los medios comunitarios en Nicaragua: la experiencia del colectivo Agentes de Cambio». En: Quórum Académico, vol. 10, n. ${ }^{\circ}$ 1, enero-junio. Maracaibo: Universidad de Zulia. Pp. 63-86. http://www.redalyc.org/articulo.oa?id=199026737003

Márquez Gómez, L. (2013). «Una TV verdaderamente comunitaria». En: Razón y Palabra, vol. 17, n. ${ }^{\circ}$ 1-82. México y Quito: Editorial Razón y Palabra. Pp. 171-180. https://www. revistarazonypalabra.org/index.php/ryp/article/view/626

Nichols, B. (1997). La representación de la realidad. Barcelona: Paidós. http://metamentaldoc.com/9_La\%20Representacion\%20de\%20la\%20Realidad_Bill\%20Nichols.pdf

Servaes, J. y Malikhao, P. (2007). «Comunicación participativa: ¿el nuevo paradigma?». En: Redes.com, n. ${ }^{\circ}$ 4. Pp. 43-60. https://www.academia.edu/566651/comunicaci\%c3\%b3n_partici pativa_el_nuevo_paradigma

Téllez Garzón, M. P. (2005). «La televisión comunitaria en Colombia: entre la realidad y la utopía». Comunicação \& Sociedade año 26, n. ${ }^{\circ}$ 43. São Bernardo do Campo: PóscomUmesp. Pp. 140-154. https://core.ac.uk/download/pdf/229066607.pdf 